Portland State University

PDXScholar

\title{
Addressing the Unmet Need : an Analysis of the Global Prevalence of Refractive Error and its Possible Solutions
}

Sonam Narayan

Portland State University

Follow this and additional works at: https://pdxscholar.library.pdx.edu/honorstheses

Let us know how access to this document benefits you.

\section{Recommended Citation}

Narayan, Sonam, "Addressing the Unmet Need : an Analysis of the Global Prevalence of Refractive Error and its Possible Solutions" (2014). University Honors Theses. Paper 42.

https://doi.org/10.15760/honors.87

This Thesis is brought to you for free and open access. It has been accepted for inclusion in University Honors Theses by an authorized administrator of PDXScholar. Please contact us if we can make this document more accessible: pdxscholar@pdx.edu. 


\title{
Addressing the Unmet Need: An Analysis of the Global Prevalence of Refractive Error and its Possible Solutions
}

\author{
by \\ Sonam Narayan \\ An undergraduate honors thesis submitted in partial fulfillment of the \\ requirements for the degree of \\ Bachelor of Science \\ in \\ University Honors \\ and \\ Science \\ Thesis Adviser \\ John P Lowery \\ Portland State University \\ 2014
}


Lacking proper health care can have many negative effects on a person, but specifically lacking vision care can hugely destroy a person's quality of life. As stated by the World Health Organization (WHO), “...Millions of children are losing educational opportunities and adults are excluded from productive working lives, with severe economic and social consequences. Individuals and families are frequently pushed into a cycle of deepening poverty because of their inability to see well". ${ }^{1}$ Vision impairment can cause a person to be excluded from their community, their workplace or education, etc., and without these connections quality of life deteriorates. According to $\mathrm{WHO}$, the major cause of vision impairment worldwide is refractive error, which is defined by them as the inability to, “...correctly focus images on the retina. The result is blurred vision, which is sometimes so severe that it creates functional blindness for affected individuals". ${ }^{2}$ Much of the need to correct refractive error is unmet, and was estimated to comprise 153 million individuals, according to $\mathrm{WHO}$ in $2006 .{ }^{3}$ Some of the possible solutions to this worldwide problem are led by the young minds of students who plan to be the future of healthcare, and this is what inspired me to research this issue. As a leader and active member of my school's pre-optometry club, I find that I am regularly involved in many service projects to help the underserved, but specifically have also been extensively involved in aiding a possible solution to global refractive error. As a contributor to a student VOSH (Volunteer Optometrists in Service to Humanity) club, I work at my school's campus to raise the issue of helping underserved areas receive

\footnotetext{
1 World Health Organization, "Sight Test and Glasses Could Dramatically Improve the Lives of 150 Million People with Poor Vision."

2 Ibid.

3 lbid.
} 
vision care, and specifically collect used eyeglasses to be re-prescribed to those in need overseas. This is the major plan and action scheme of many VOSH organizations around the world, to "provide humanitarian missions in efforts to meet the demand for vision care in developing countries". ${ }^{4}$ Many of these organizations do so by gathering, sorting, and transporting recycled eyeglasses. Recycled eyeglasses are low cost, and ideally the perfect solution to help underserved areas with populations that cannot afford refractive services, or at least that is what is often assumed. To evaluate and choose the best solution to lessen global refractive error, the global impact of refractive error must be statistically quantified. In order to determine whether or not using recycled spectacles to aid the unmet refractive service need is the best solution, pros and cons of this type of program must be studied. From there changes or alternative solutions can be introduced, and a common one that I plan to study is the production of ready-made spectacles instead of recycled ones. My objective in this paper is to determine whether recycled spectacles, dispensed by volunteer vision care organizations, are the best option for solving the main cause of vision impairment worldwide, uncorrected refractive error. I will do this by breaking my paper into three parts of analysis. The first section serves to provide an introduction to the prevalence of refractive error worldwide by showing its statistical significance in the WHO regions studied. The second part will analyze the effectiveness of glasses recycling programs as a solution by looking at costs, long term effects on populations served, etc. The third section will be a similar analysis of

\footnotetext{
${ }^{4}$ Lowery et al., "Change in Visual Acuity Status of Patients Served by a Humanitarian Vision Clinic in Mexico."
} 
an alternative to glasses recycling programs, producing local 'ready-made' glasses. Lastly, I will then relate the pros and cons of both solutions back to the data analyzed in the first part of the paper to determine the best solution.

Part 1 - Analysis of Global Refractive Service Needs

The first part of my research objective is to define why my issue, refractive error, is important by evaluating the epidemiological evidence. WHO defines uncorrected refractive error as the top cause of vision impairment in their 2010 Global Data on Visual Impairments publication $(43 \%)^{5}$, but does not break down the statistic amongst each of their 6 WHO regions (African, Region of the Americas, Eastern Mediterranean, European, Southeast Asian, and Western Pacific).

5 World Health Organization, "Global Data on Visual Impairments 2010." 


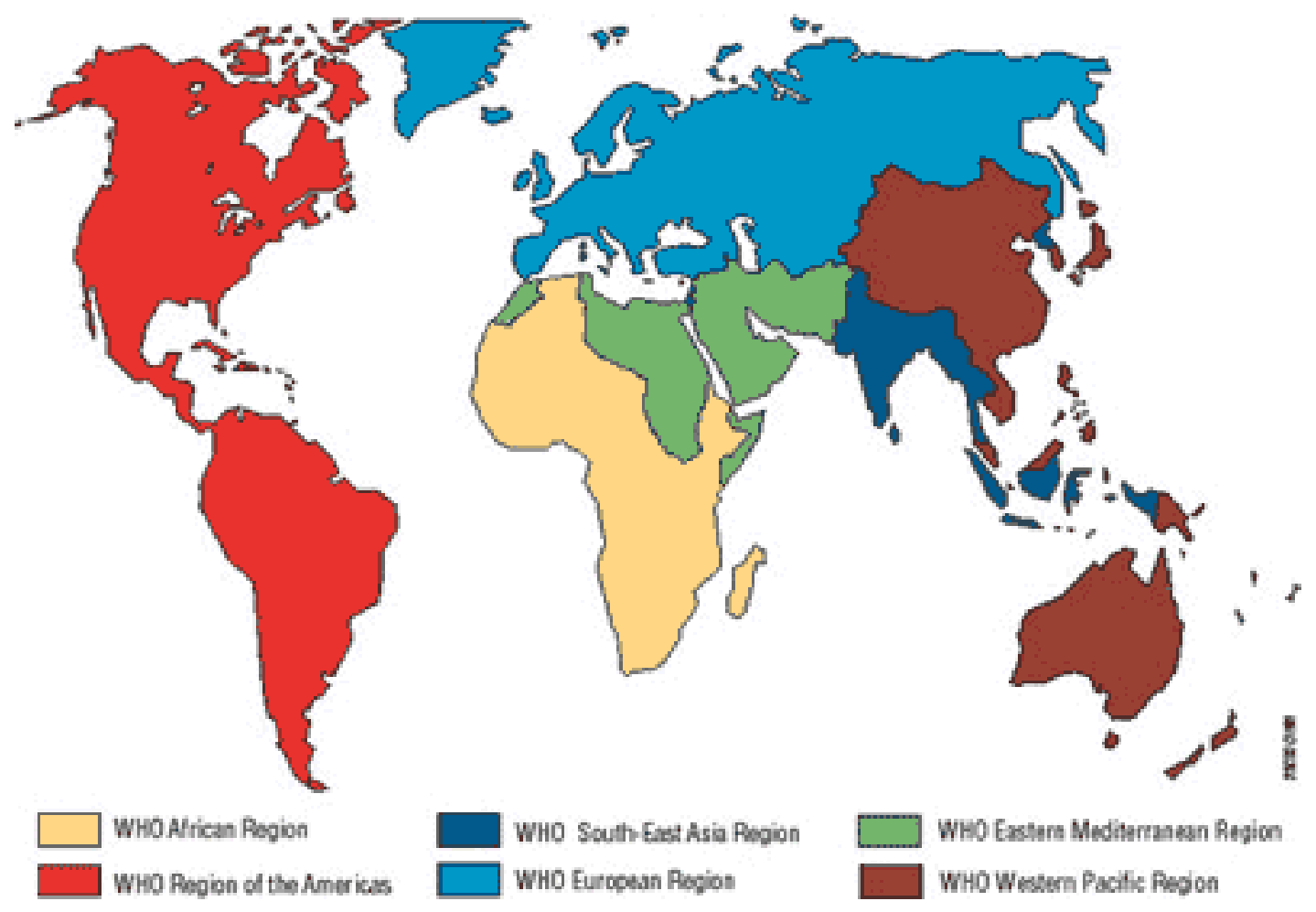

My first process is to find specific data on refractive error prevalence on one country or more from each of these regions, excluding the Eastern Mediterranean and European region. I have excluded these due to difficulty finding studies in these regions for all 3 parts of my paper, and also because these two regions encompassed the fewest countries of all the 6 regions. My method of finding the data I needed was library database research for quantitative articles showing refractive error as the main cause of vision impairment. My hypothesis for this section is that not only is refractive error the top cause of visual impairment on a total global population scale, but that it is also the top cause in at least 1 country in each WHO region studied. The purpose of this hypothesis is to show the "widespread" global prevalence of refractive error as a top vision care problem. In this case I define 'widespread' as 
showing that while refractive error may be the top cause of vision impairment in the world based on total population statistics, it is also the top cause in each of the WHO regions studied, regardless of population size in each region.

Fig. 2A

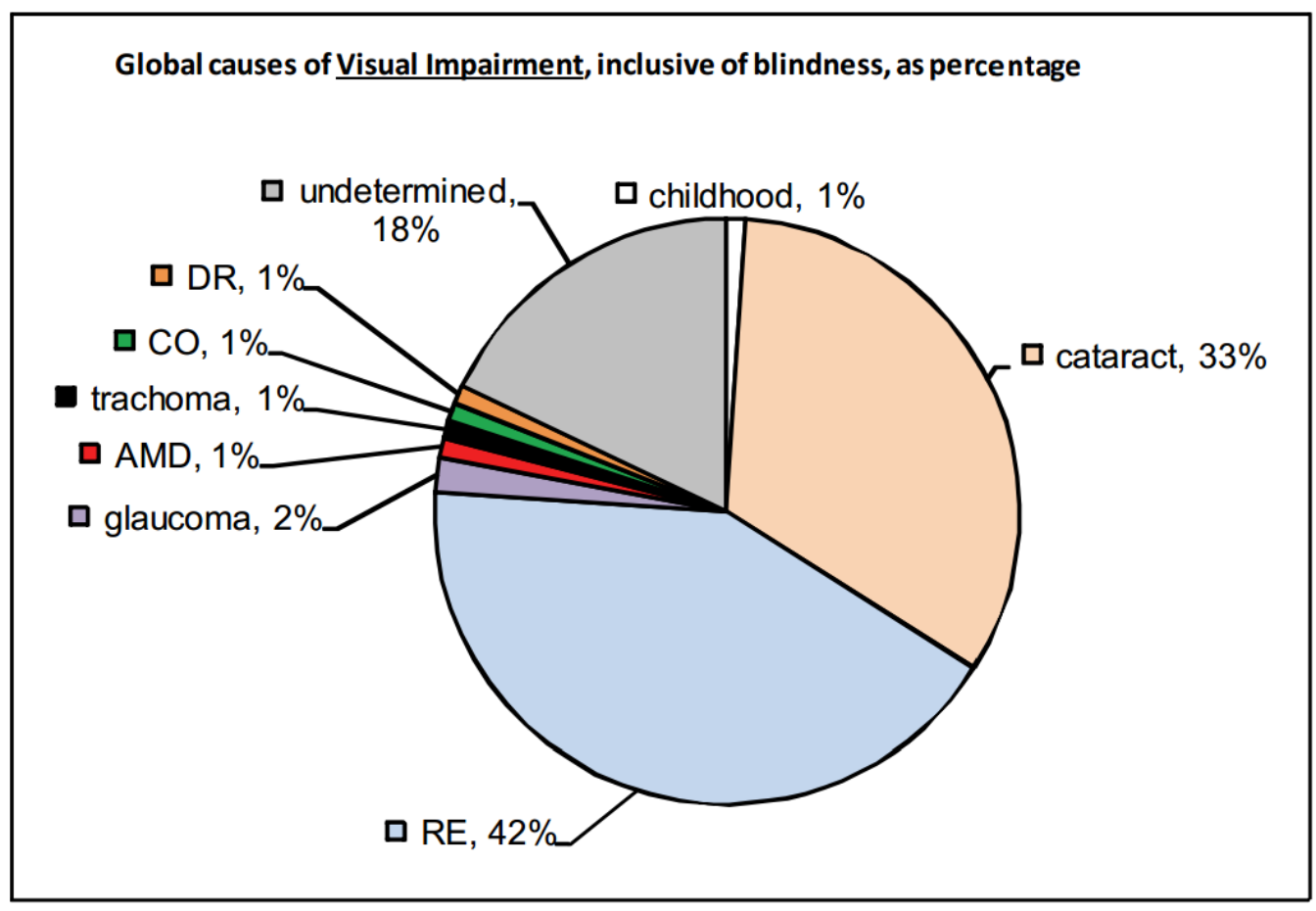

6

The first region WHO region I studied was the South-East Asia region, with a focus on the large country of India encompassed by that region. Articles I chose to extract my data from were written by Dandona and Dandona, major writers and contributors of the field of visual impairment. The first article had the methodology of a "literature search to identify information from different parts of the world on the magnitude of blindness due to refractive error from population-based surveys of blindness published in 1990 or later". ${ }^{7}$ Their studies showed that blindness due to

\footnotetext{
6 Ibid.

7 Dandona and Dandona, "Refractive Error Blindness."
} 
refractive error was as high as $.36 \%$ in the population, which was roughly 1 in every 280 people in India. An important piece that stood out in their studies said "Recent data from India suggest that, in terms of blind-person-years among the individuals who are blind currently, the burden on society due to refractive error blindness is about twice that due to cataract blindness (7)."8 To determine specifically what 'burden' meant in this statement, another literature review article by Dandona and Dandona filled in: "the onset of visual impairment due to natural refractive error sets in at a younger age than the other major causes, it is responsible for a much larger number of blind years lived by a person than most other causes if left uncorrected $[\underline{5}, \underline{14}]$. It was estimated in an Indian state that blindness due to uncorrected natural refractive errors resulted on average in over 30 years of blindness for each person as compared with 5 years of blindness due to untreated cataract for each person [14]."” This explanation connects back to the idea presented in the introduction of my paper regarding the socio-economic impact of visual impairment on a society. What Dandona and Dandona defined as the "the most common cause of visual impairment in the world"10 has a very high socioeconomic impact due to its ability to hinder one's working abilities earlier in life than cataracts or any other cause of visual impairment. This impact made by refractive error on youth (termed ambylopia, which stems from high refractive error in childhood) was found to be statistically significant in the same India study as well with " $0.06 \%$ of the population blind due to refractive-error-related

\footnotetext{
8 Ibid.

9 Dandona and Dandona, "What Is the Global Burden of Visual Impairment?". 10 Ibid.
} 
amblyopia", a condition that led to permanent vision loss if not corrected early in youth". ${ }^{11}$ Collectively, this literature review by Dandona and Dandona showed refractive error to be the leading cause of vision impairment in this WHO region (outweighing cataracts, a close second top cause), as well as shed light on the concept that amblyopia (stemming from untreated refractive error in youth) as a major contributor. Another statistical survey done in Singapore amongst the Chinese, Malay, and Indian residents there showed similar results in regards to refractive error being the leading cause of vision impairment: "Overall, approximately $70 \%$ of the populations needed eye care services and more than $30 \%$ had more than one need. The age-standardized proportion of people who need RS (refractive services), AES (eye examination services), CSS (cataract surgery services), and LVS (low vision services) were 65.3\%, 22.4\%, 12.5\%, and 0.5\%, respectively, in Chinese. These figures were $49.6 \%, 33.6 \%, 11.0 \%$, and $0.7 \%$, respectively, in Malays, and 55.6\%, 40.0\%, $13.4 \%$, and $0.8 \%$, respectively, in Indians". ${ }^{12}$ This study showed that in each of the races surveyed in the area, refractive error (RS) was the leading cause. Overall, the literature reviews from Dandona and Dandona and the survey done in Singapore both help to demonstrate the major cause of vision impairment in the South-East Asia WHO region.

The second WHO region I reviewed was the Region of the Americas, and I specifically looked at a study done in a Mexican-American population within that region. The methodology of this study was to randomly select and ophthalmically

\footnotetext{
11 Dandona and Dandona, "Refractive Error Blindness."

12 Zheng et al., "How Much Eye Care Services Do Asian Populations Need?".
} 
evaluate participants. Their studies found that "The prevalence of presenting visual acuity worse than $20 / 40$ was $8.2 \%$, with uncorrected refractive error accounting for 73\% of the impaired acuity". ${ }^{13}$ This statistic was positively correlated with increasing age and low income in addition. This study was not as expansive as the others I reviewed, but satisfied the goal of statistically signifying that refractive error was the leading cause of visual impairment in part of the Region of Americas.

The third WHO region I examined was the African region, and I selected a study done in West Africa (in Tema, Ghana). The methodology of the study was similar to those previous, the local population was randomly sampled and examined by an ophthalmologist to determine prevalence and causes of visual impairment and blindness. One factor that stood out in this study however was that the persons sampled were of age forty and older only. Due to the fact that many of the studies done in the African region focused primarily on the older population, and due to difficulty of finding a study that surveyed refractive error in this region, I chose to evaluate this study regardless of a limited age range being sampled. Of the 5603 participants, results showed that "the prevalence of visual impairment and blindness was $17.1 \%$ and $1.2 \%$, respectively". ${ }^{14}$ Although this study did not compare the prevalence of refractive error to that of other causes of visual impairment, it did go on to say that "after refraction and spectacle correction, the prevalence of visual impairment and blindness decreased to $6.7 \%$ and $0.75 \%$, respectively, suggesting

\footnotetext{
13 Muñoz et al., "Blindness, Visual Impairment and the Problem of Uncorrected Refractive Error in a Mexican-American Population."

${ }^{14}$ Budenz et al., "Blindness and Visual Impairment in an Urban West African Population."
} 
that refractive error is the major correctable cause of visual impairment and blindness in this population". 15 This study concluded that because refractive services lessened the burden of visual impairment on the population sampled by over $60 \%$, it is indeed the major cause of visual impairment in the population, regardless of what the other causes of impairment are. These statistics satisfactorily say that refractive error is a leading cause of visual impairment in part of the African WHO region.

The last WHO region I evaluated was the West Pacific region. Of this region, the study I chose to do a literature review of was located in Viti Levu, Fiji Island. This study was again aimed at examining the older population (those of age forty plus), and specifically looked at the causes of blindness, low vision, and visual impairment in those of that age bracket. This study was therefore similar to the one I reviewed for the WHO African region, and again in this occurrence I chose to accept the results of this study in particular for my research. This was again due to lack of finding a better study that detailed percentages of refractive error in the population surveyed. The methodology of this study was again a random sampling method to determine the causes of vision loss in the population surveyed, and yielded statistics of the prevalence of visual impairment, low vision, and blindness in those surveyed. Low vision was termed as presenting better visual acuity than that of those with blindness, but worse than those who would be considered simply

\footnotetext{
$15 \mathrm{lbid}$.
} 
visually impaired. Of the 1381 people surveyed, it was shown that "Among participants with low vision, uncorrected refractive error caused 63.3\%". ${ }^{16}$ Not only this, but a table in the study reviewing the statistics showed that uncorrected refractive error was responsible for $38.4 \%$ of visual impairment, with cataracts being a close second leading cause at 35.4\%. These statistics summed together showed that refractive error was the leading cause of visual impairment and low vision in this Fijian population, and therefore part of the West Pacific WHO region.

Part 2 - Analysis of VOSH Spectacle Recycling Programs as a Possible Solution

Having gained a general idea of the refractive service needs in each WHO region studied in the first part of my thesis, the second part was to research possible solutions. In this section, I namely looked at the effectiveness of spectacle recycling programs as an aid to the unmet global refractive service need. My research involved studying spectacle recycling programs (namely VOSH) to determine the pros and cons of this possible solution, and determining how well it met the cause established by section 1 . This portion of the paper also involved library database research, again specifically for articles quantifying data. The potential findings I was looking for were at least 1 article with quantitative data each on both a bad facet and good facet of this kind of program/solution to the issue I presented. I also

\footnotetext{
16 Ramke et al., "Prevalence and Causes of Blindness and Low Vision among Adults in Fiji."
} 
specifically wanted data on how well the program served the populations it serviced using recycled spectacles, so I could obtain a statistical success rate.

The first article I studied pertained to the WHO Region of the Americas, specifically Mexico. In this study the statistical outcome of a student VOSH (Volunteer Optometrists in Service to Humanity) trip to Mexico was measured. The spectacles prescribed during their refractive services were recycled ones (collected in the USA through donation drive programs). Their studies concluded that "A total of 413 distance spectacle corrections and 670 near corrections were dispensed within the study sample of 813 subjects. Those entering the clinic with distance visual acuity of $20 / 200$ or worse caused by refractive error and/or ocular disease totaled $78(9.6 \%)$, whereas those exiting with this level of acuity totaled $32(3.9 \%)$. Those who entered with distance acuity constituting visual impairment totaled 105 (12.9\%), whereas those exiting with distance visual impairment totaled 31 (3.8\%). Those entering with near visual acuity of 20/70 or worse totaled 403 (49.6\%), whereas only 27 (3.3\%) exited the clinic with visual impairment at near"..17 This shows that at least $60 \%$ of the refractive services needed were satisfied by the present supply of recycled glasses. Specifically, the largest improvement was shown in the population served with near vision acuity (mostly due to presbyopia), with 93\% of their needs met. In addition to this, "Of 86 patients with cataracts, 74 showed improved visual acuity with refractive correction".18 This was an $86 \%$ rate of success for the improvement of vision in cataract patients. As mentioned before in

\footnotetext{
17 Lowery et al., "Change in Visual Acuity Status of Patients Served by a Humanitarian Vision Clinic in Mexico."

$18 \mathrm{lbid}$.
} 
the first part of the paper, cataracts have been known to be the second biggest cause of vision impairment globally and are not curable through refractive services, but instead require surgery. The fact that this study showed that refractive services could improve vision in such a large number of cataract patients in addition to those who solely needed glasses is an important thing to be noted. Overall, this study showed that the majority of the population needs (near visual acuity services) were met by the recycled spectacles prescribed. In addition to this, they were able to significantly aid at least $60 \%$ or more participants with cataracts and other vision impairments besides hyperopia.

The second study I looked at that used recycled spectacles as a solution was one done in Tuvalu, an island in the WHO West Pacific region. The sole purpose of the study was to statistically evaluate recycled spectacles for satisfying the visual service needs of the citizens of Tuvalu. They reported that " $62.7 \%$ had $>1.00$ DC and/or $>0.50 \mathrm{D}$ anisometropia, 30\% were broken and/or scratched and 50\% were uncomfortable or cosmetically unacceptable. Only $13 \%$ were optically satisfactory, physically intact, and cosmetically appropriate", with anisometropia defined as having unequal refractive power in the two eye lenses. ${ }^{19}$ This study therefore showed something that was completely overlooked in the previous study I analyzed: the percentage of recycled spectacles that were damaged in the collection/recycling process and unable to be utilized. The study went on to say "For the other $83.1 \%$ (266), if the cache contained at least 5538 spectacles, each would eventually find a

\footnotetext{
${ }^{19}$ Ramke, Du Toit, and Brian, “An Assessment of Recycled Spectacles Donated to a Developing Country."
} 
suitable pair" 20 , with $83 \%$ referring to the percentage of the population of Tuvalu whose refractive service needs could be satisfied by the recycled spectacles available. The study went on to criticize the practice of glasses recycling, saying that with only $13 \%$ in useable condition, the currency costs and labor costs of collecting, cleaning, transporting, etc. of recycled glasses was not a worthwhile cause. It went on to conclude that when the participants were offered with the option of buying new, ready-made glasses " $82.5 \%$ (264/320) of the Tuvaluans, after refraction and with dispensing help, were sufficiently happy with the appearance and function of new ready-made spectacles for distance or near use that they paid AUD10 per pair" (\$9.26 USD). ${ }^{21}$ Overall, this study showed that around 83\% of the population served could be satisfied by the supply of recycled glasses, but did not omit details regarding how much of the supply was actually in useable condition $(13 \%)$ rather than broken or damaged. It also presented a high statistic of individuals satisfied by paying a low price to purchase a new pair of ready-made glasses rather than accepting used ones.

On the note of exploring the "real" cost of recycled spectacles, I reviewed an article with the purpose of solely defining that. The article discusses how recycled spectacles are ideally a great solution, being extremely financially sustainable, but how actual results of collecting and distributing them show something quite different. The methodology used in the study was examining boxes of recycled spectacles, as well as estimating the total cost of cleaning, processing, transportation, and delivery. Their results showed that "Only 7\% of the 275 recycled spectacles

\footnotetext{
$20 \mathrm{lbid}$.

$21 \mathrm{lbid}$.
} 
analyzed were suitable for use. The relatively small proportion of useable spectacles contributed to the high societal cost of delivering recycled spectacles, which was found to be U.S. $\$ 20.49$, more than twice the cost of supplying ready-made spectacles". ${ }^{22}$ This percentage is similar to the one found in the previous study indicating that only $13 \%$ of recycled glasses were able to be used. In addition to being similar to the last study, this article brings up the new point of delivery costs being twice that of a pair of ready-made spectacles, which is an important point to be noted. Overall, this study and the previous one help to conclude that the "real" cost of recycled spectacles is not as inexpensive and sustainable as it may seem, as well as introduce a cheaper, possibly more efficient alternative, ready-made glasses.

Prior to moving on with the discussion of the major problems highlighted in the above articles in regards to recycled eyeglasses, there are some important factors from the research thus far that need to be noted. Both of these articles concluded that a very small percentage of recycled eyeglasses were able to be utilized, and that the costs of labor and transportation of said eyeglasses outweighed the benefits provided to the population serviced. One thing to consider is that neither of the studies detailed the collection and sorting process that determined what recycled eyeglasses were specifically chosen to be taken abroad. The recycled eyeglasses likely came from different sources, and therefore different were subjected to various sorting processes depending on which lens library they came from. Certain lens libraries are even built to match the refractive demographics of the population they intend to serve, and this too is an important

\footnotetext{
22 Wilson et al., "Real Cost of Recycled Spectacles."
} 
variable. While it is true that the idea of hauling a "raw" stock of recycled eyeglasses overseas is impractical, as mentioned in the above articles, it is not detailed whether or not this was done in either study, and information regarding the sorting process and where the glasses were obtained are not explained either. Due to these multiple factors not being explored, it cannot necessarily be said that the costs of sorting and transportation outweigh the costs saved by prescribing recycled glasses rather than ready made ones; various studies will likely have different percentages of recycled glasses utilized/prescribed on site due to their differing collection and selection processes.

Moving on with the discussion prompted by the articles described above, it seems as though the main problem presented with recycled glasses as a solution to unmet global refractive service need is the collection and transportation of them. Specifically, many glasses are damaged during collection, sorting, and transporting, which results in a large percentage of unusable glasses and an unsustainable program. In addition, it is challenging to find used spectacles that are suitable for individuals with unusual refractive conditions, particularly high astigmatism. Therefore, organizations may have to transport thousands of glasses just to match the refractive needs of a very few people. To further explore the process that recycled spectacles go through when being collected, I analyzed an article surveying volunteer organization and their responses to questions regarding glasses recycling programs they lead. When asked about their use of recycled spectacles, organizations said "easier to obtain $(22,71.0$ percent $)$ and that they are less expensive $(20,64.5$ per cent). One organization stated: ' $\ldots$. the use of recycled 
products is not best practice and [we] would not work in this way if there was a cost effective alternative. We are committed to phasing out the use of recycled spectacles ... as soon as an effective alternative can be found."' ${ }^{23}$ This shows that volunteer organization are aware of the problems regarding the effectiveness of recycled spectacles, but are bound by costs. The article goes on to conclude, "Despite the availability of inexpensive and high quality readymade spectacles 24,25 that provide sufficient visual correction, 25-28 the vast majority of volunteer organizations continue to dispense recycled spectacles". ${ }^{24}$ Near the end of the article, suggestions are made to volunteer organizations to "recognize the need for increasing the local eye-care workforce in developing countries" and "look past the individual patients to the eye care that is, or is not, available to the country as a whole." 25 , and therefore encourage a long term, locally available solution to the problem. The article goes on to continue to emphasize that all the volunteer organizations combined could not meet global refractive service needs, but can provide a positive influence to a permanent solution. Overall, this article provides an insight into the function of volunteer organizations that run glasses recycling drives, and how they can better serve the community they wish to aid in the long term.

Lastly, another article I reviewed discusses the same issue of volunteer organizations and recycling drives not being the best fit solution, saying "Considerable manpower, materials, money and logistical resources are used in conducting these short-term missions, yet scarce evidence exists regarding their

\footnotetext{
23 Pearce and Pearce, "Addressing Refractive Error Visual Impairment."

$24 \mathrm{Ibid}$.

$25 \mathrm{lbid}$.
} 
cost effectiveness or the efficacy and long-term impact of these interventions. The provision of direct clinical services by most foreign volunteers does not directly build local capacity and may hinder development of sustainable local services"26. The article goes on to urge more exchange between national and international organizations to create a common goal and public health approach, as well as "local capacity building", the idea of building up services provided by locals versus foreign teams. The study goes on to say "it should be recognized that sustainable community services cannot rely on uncertain or erratic supplies of spectacles"27, as well as remind us again that "The resources used to sort, label and box donated eyeglasses, ship them to another country and then get them to a field location offsets the actual value of these glasses"28. This statement matches up with the study analyzed earlier that says the cost of recycled glasses eventually outweighs the cost of ready-made ones. In addition to this fact, it is explained in this study how delivering recycled glasses hinders the development of local services and supplies. Overall, this study is similar to the previous one, but also explores how recycled glasses could actually be an "unsustainable" solution due to its effect on the development of the countries it aids. This effect could stretch as far as taking local optical resources out of business if volunteer organizations don't work with them to build permanent solutions for eye care services.

\footnotetext{
${ }^{26}$ Vincent et al., "The Rationale for Shifting from a Voluntary Clinical Approach to a Public Health Approach in Addressing Refractive Errors."

27 lbid.

$28 \mathrm{lbid}$.
} 
Part 3 - Analysis of an Alternative Solution, Locally Dispensed Ready-Made Spectacles

The third part of my research is to study an alternative to spectacle recycling programs, ready-made spectacle dispersal. I again wanted at least 1 statistically significant pro and con article each for this section, with both containing quantitative data, and again utilized the library database to conduct my literature review. As with the previous two parts of my paper, the research done was kept consistent in that all the studies were from the $4 \mathrm{WHO}$ regions I originally aimed to analyze. Another goal for this section was to determine the most sustainable approach to long-term global refractive service care after analyzing all the data presented in my thesis.

The first study I reviewed goes back to the WHO region of South-East Asia, specifically Bangladesh, to determine how feasible it is to serve that population's refractive service needs with ready-made spectacles. A portion of Bangladesh's population was statistically surveyed (the same methodology used in studies discussed in part one of my paper), and it was determined that "Of the 1142 subjects who would benefit from spectacles, 827 (72.4\%) would be suitable for off-the-shelf spectacles" not including those with presbyopia (far sightedness due to aging), which would increase the percentage considerably. ${ }^{29}$ Of the population suitable for off-the-shelf, or ready-made, spectacles consisted of "(41.1\%) hyperopes (more

\footnotetext{
${ }^{29}$ Bourne et al., "Correction of Refractive Error in the Adult Population of Bangladesh."
} 
than_1 D) and 263 (31.8\%) myopes"30. This indicates that a higher percentage of hyperopic people could be satisfied by the ready-made spectacles. The article went on to note "Hyperopes (more than_0.5 D) were more likely to wear spectacles than myopes (less than_0.5 D). Hyperopia may be more debilitating in a population that is predominantly rural and either unemployed or involved in manual work". ${ }^{31}$ This seems important to note because in the study done in Mexico with recycled spectacles, a larger portion of hyperopic patients were served there as well, and there was therefore a higher demand for near vision correcting glasses just like in this study. (This may indicate a higher need for near vision correcting glasses specifically, and needs further study). A study done to further these findings of ready-made glasses suitability was done in the same WHO region, but in India, also evaluated ready-made spectacles dispersed to the surveyed population. The goal of this study was to specifically evaluate the satisfaction of the population served with ready-made glasses versus custom made ones, and found a satisfaction rate of over 90\%. ${ }^{32}$ To explain the potential of ready-made spectacles versus custom made ones, an Australian study leaning towards a similar solution states "In many countries, poor supply of refraction services, supply of spectacles, and economic factors may limit access of the general population to refractive correction. The cost of individually made up spectacles would be prohibitive for large scale supply in many developing areas. The provision of ready-made spectacles provided in bulk at low cost across a range of refractive corrections could potentially reduce this cost.

\footnotetext{
30 Ibid.

31 lbid.

32 Keay et al., "A Randomized Clinical Trial to Evaluate Ready-Made Spectacles in an Adult Population in India."
} 
Ready-made spectacles have already shown great benefit with reading spectacles readily available for the presbyopic population". ${ }^{33}$ All in all, these studies state that the dispersal of ready-made spectacles was quite successful, with a rate of success similar to that of the glasses recycling programs, but without any waste of resources, cash, or labor unlike the latter.

The second study I analyzed was done in the WHO Region of the Americas, specifically in Nicaragua, and was very similar to the survey conducted in India, mentioned above. "Ready-made plus sphere spectacles (bifocals or single-vision readers) were dispensed to $95.4 \%$ of those examined" 34 in this study done in Granada, Nicaragua. Like the previous study participants were highly satisfied, but the new information found in this study was the amount of money participants were willing to pay, which were on average: “US\$ 18.39 to replace the bifocals and US\$ 16.67 to replace the readers" 35 . This value was higher than the cash value stated in the article in part two discussing the cost of ready-made spectacles versus recycled ones, which said that the cost was roughly $\$ 10$ USD. If it is assumed that the real cost of a pair of ready-made spectacles truly is $\$ 10$ USD, the fact that Nicaraguan participants were willing to pay more is a good sign indicating that they are willing to locally invest in their vision care.

A slightly different study done in the African WHO region surveyed presbyopic spectacle coverage specifically (with the term presbyopia meaning impaired near vision due to old age, not irregular eyeball shape, which is hyperopia).

\footnotetext{
33 Keeffe et al., "Correction of Refractive Error in the Victorian Population."

34 "Use of Ready-Made Spectacles to Meet Visual Needs in a Low-Resource Adult Population."

35 Ibid.
} 
Although this survey addresses the very specific issue of dispensing ready-made spectacles to aid the presbyopic population surveyed, what stood out was that participants were surveyed on what they were willing to pay for the spectacles as well, similar to the above study. Overall results of the study show that dispensing ready-made spectacles was a successful solution, saying that at a follow up appointment "175 (93.6\%) of 187 participants given spectacles still had them. Mean satisfaction was high at $89.5 \%$ ". ${ }^{36}$ This result jives well with the other successful results found in this part of my thesis, but a unique perspective provided in this specific study was asking how much participants were willing to pay for their readymade glasses both before being dispensed and after the follow up appointment. It was found that "The mean amount participants were willing to pay for spectacles had increased from 2.17 USD at baseline to 3.14 USD at follow-up"37, which was an increase of a whopping $45 \%$. Although the overall cost that the participants were willing to pay for their ready-made glasses was lower than the costs stated in the studies reviewed previously, the main takeaway was that satisfaction with their new, ready-made glasses made patients willing to pay up to $45 \%$ more of what they previously had paid. Overall, the studies done in Nicaragua and Africa imply that locals desiring refractive services are very willing to do what the articles reviewed in part two suggested: invest in their local services and eyewear available, as opposed to received foreign aid through glasses recycling programs.

\footnotetext{
36 Laviers et al., "Presbyopic Spectacle Coverage, Willingness to Pay for Near Correction, and the Impact of Correcting Uncorrected Presbyopia in Adults in Zanzibar, East Africa."

$37 \mathrm{lbid}$.
} 
Before concluding that ready-made spectacles are an option worth investing in however, some details that these studies did not divulge should be noted. Firstly, none of the studies reviewed for this section compared their results with those of prescribing recycled eyeglasses to the same population, so the efficiency and efficacy of ready-made glasses versus recycled ones at meeting the vision care needs of the population cannot be directly compared. In addition, these studies specifically had a positive bias on how the needs of most of the populations serviced could be met by ready-made spectacles rather than custom made or recycled, and how much participants were willing to pay for them. They did not detail how and where the ready-made spectacles were produced, so it was not clear how accessible these ready-made glasses were to the populations serviced, or if it was the most financially sustainable option to invest in them (considering that they may be produced in factory in a country far away rather than locally). The information regarding the quality and available selection of these glasses was not detailed either (only the percentage of the population's vision care needs that were satisfied by them, for one of the studies). Due to the fact that the overall sustainability of the production process for the ready-made spectacles used in these studies was not addressed, they cannot necessarily be advocated as a better fit solution as opposed to recycled spectacles.

To return back to the research question at hand of proving the significance of refractive error globally and then finding the best fit solution, I will now review the results yielded by my literature review. In the first portion of the thesis, the regions of the world were broken down according to the World Health Organization regions 
map, and the objective was to find the leading cause of vision impairment in four of the regions to demonstrate that refractive error is not only the leading cause of vision impairment by total population affected, but also in each region of the world regardless of socio-economic status differences. This hypothesis was proved to be true, and established the importance of solving the unmet need of refractive error as a new and upcoming cause of vision impairment globally. The second part of the thesis served to analyze volunteer organization led spectacle recycling programs as a possible solution to the problem. Through an extensive literature review it was found that although the programs superficially present a very high success rate, the total labor and cash cost of collecting and transporting glasses may outweigh the benefits. An additional analysis of this data showed that the details of the collection process for each study as well as how/which spectacles were chosen to be taken abroad were omitted, which means that it cannot be generalized that the percentage of recycled glasses actually prescribed during humanitarian missions is outweighed by the percentage "wasted". While this presents the problem of whether or not the programs are as financially sustainable as assumed, the new major problem arose of having a long term public health outlook to help underserved populations in the long term, and not just in the short term through volunteer trips. It was explained that while bringing recycled spectacles and other resources from developed countries helped in the short term, it did not help to create a system where locals relied on their local eye care services and resources available, and sometimes even counteracted any progress made towards countries developing their own vision care solutions. 
At this point the thesis transitioned into part three, which explored the alternative solution of dispensing ready-made spectacles locally in countries. The results of the studies analyzed for this section showed very positive results, similar to those of the glasses recycling programs, but without any hidden costs discovered later in the research. As an additional plus, the solution claims to be simple and feasible to establish as "Many developing countries do not have optometrists or others trained in refraction or dispensing a prescription of spectacles. Ready-made spectacles could easily be provided by paramedical staff with basic training in subjective refraction and dispensing". ${ }^{38}$ Upon additional analysis of what these studies did not divulge, questions were raised regarding the production location and process of these glasses, as well as the available selection and quality of them. Due to these details being left out, it could not be concluded that ready-made spectacles were the best fit solution for populations in need of refractive services, only that they were fairly good at meeting the visual needs of many populations studied. Of course, more study has to be done on how successful these programs are in multiple countries with various socio-economic statuses, with the consideration of how financially sustainable they are in the long run. The articles studied frame it as a solution with great potential, with high patient need satisfaction rates, increased rates of what patients are willing to pay for such resources, and most importantly a sustainable solution in the sense of creating reliance of underserved countries on locally available resources rather than foreign ones, a health care perspective that could greatly reduce the prevalence of refractive error worldwide in the future. This

\footnotetext{
${ }^{38}$ Keeffe et al., "Correction of Refractive Error in the Victorian Population."
} 
statement yields to be true when comparing recycled eyeglasses (coming from countries overseas) to ready-made spectacles assuming that the ready-made spectacles are available locally and affordable to those in the population serviced. If they too are coming from a country overseas, then they cannot be presented as a better solution to help countries rely on local sources of eyecare. What is then identified as the main facet of the best solution for global refractive error is not so much the source/type of glasses as much as it is the method of utilization of them, or rather, the eye care services distributing them. One could go on with researching whether or not recycled eyeglasses or ready-made eyeglasses are most suitable for a needy population based on cost and effectiveness, but as mentioned by the VOSH commentary earlier in the paper, the future of the solution for global refractive error lies in populations learning to rely on local resources rather than sporadic help/resources from humanitarian groups. This new outlook has shaped the future of VOSH, and their new website sustainability statement reads, "The mission and vision of VOSH evolved over the years from short-term missions to the establishment of permanent clinics, provide educational program, research the epidemiology of refractive error, and partner with other NGOs"39. Groups such as the student VOSH my optometry club is affiliated with, the Pacific University of Optometry AMIGOS program, have also incorporated similar values into their mission statement, saying "AMIGOS strives to provide a resource for continued care within the communities it serves. This plugs the patients into the existing health

\footnotetext{
39 "Sustainable Projects | VOSH International."
} 
care system, and perpetuates a stronger health care program" 40 . A look at the AMIGOS New Trip Assessment Form shows that many questions are asked prior to making a humanitarian mission to ensure that they are providing continued, sustainable care ${ }^{41}$. These questions include finding out whether or not current health organization plans exist in the area, if trainings and education can be provided to locals through the trip, if glasses can be obtained locally for a reasonable cost, etc. It is obvious now that what needs to be invested in at this point to help refractive error worldwide is not so much a specific type of eyeglasses, but instead a focus on training more eye health professionals in underserved countries so that a sustainable, permanent model of vision health care can be encouraged in these countries. Once such sources are established and easily accessible by all populations in the country, it can then be researched what type of eyeglasses satisfy the majority of the needs of that specific population as well fit the budget of what they are willing to spend. For now all that can be concluded is that the practice of providing recycled eyeglasses or ready-made ones should not necessarily be discontinued (and that one is not a better option than the other), but that the delivery of these resources should be changed to allow countries to learn how to prescribe and distribute the resources themselves through local eye health models rather than those done through foreign humanitarian groups.

\footnotetext{
40 AMIGOS Eye Care, "AMIGOS Eye Care - Purpose \& Mission Statement."

41 Dina Hamideh, O.D. and Kevin Helmuth, O.D. (1994) and Edited/Updated by John P. Lowery, O.D., M.Ed., Brian Silverman, O.D. (2008) and Allison Hoppert, O.D. (2009), "AMIGOS Eyecare Manual."
} 


\section{Bibliography}

AMIGOS Eye Care. "AMIGOS Eye Care - Purpose \& Mission Statement." AMIGOS Eye Care. N. p., 2013.

Bourne, Rupert R. A. et al. "Correction of Refractive Error in the Adult Population of Bangladesh: Meeting the Unmet Need." Investigative Ophthalmology \& Visual Science 45.2 (2004): 410-417. www.iovs.org. Web. 12 Nov. 2013.

Budenz, Donald L. et al. "Blindness and Visual Impairment in an Urban West African Population: The Tema Eye Survey." Ophthalmology 119.9 (2012): 1744-1753. ISI Web of Knowledge. Web.

Dandona, Lalit, and Rakhi Dandona. "What Is the Global Burden of Visual Impairment?" BMC Medicine 4.1 (2006): 6. www.biomedcentral.com. Web. 7 Mar. 2014.

Dandona, Rakhi, and Lalit Dandona. "Refractive Error Blindness." Bulletin of the World Health Organization 79.3 (2001): 237-243. Print.

Dina Hamideh, O.D. and Kevin Helmuth, O.D. (1994), and Edited/Updated by John P. Lowery, O.D., M.Ed., Brian Silverman, O.D. (2008) and Allison Hoppert, O.D. (2009). “AMIGOS EYECARE Policies, Operation, and Procedures Manual for Engaging in Humanitarian Services." n. pag. Print.

Keay, Lisa et al. "A Randomized Clinical Trial to Evaluate Ready-Made Spectacles in an Adult Population in India." International Journal of Epidemiology 39.3 (2010): 877-888. ije.oxfordjournals.org.proxy.lib.pdx.edu. Web. 12 Nov. 2013. 
Keeffe, Jill et al. "Correction of Refractive Error in the Victorian Population: The Feasibility of 'off the Shelf Spectacles." British Journal of Ophthalmology 85.11 (2001): 1283. Print.

Laviers, Heidi R. et al. "Presbyopic Spectacle Coverage, Willingness to Pay for Near Correction, and the Impact of Correcting Uncorrected Presbyopia in Adults in Zanzibar, East Africa." Investigative Ophthalmology \& Visual Science 51.2 (2010): 1234-1241. www.iovs.org.proxy.lib.pdx.edu. Web. 12 Nov. 2013.

Lowery, J P et al. “Change in Visual Acuity Status of Patients Served by a Humanitarian Vision Clinic in Mexico." Optometry (St. Louis, Mo.) 79.2 (2008): 70-77. NCBI PubMed. Web.

Muñoz, Beatriz et al. "Blindness, Visual Impairment and the Problem of Uncorrected Refractive Error in a Mexican-American Population: Proyecto VER." Investigative Ophthalmology \& Visual Science 43.3 (2002): 608-614. Print.

Pearce, Matthew G, and Nicole Pearce. “Addressing Refractive Error Visual Impairment: Volunteer Organisations' Alignment with Vision 2020 and Public Health Principles." Clinical and Experimental Optometry 95.6 (2012): 583-589. Wiley Online Library. Web. 11 Dec. 2013.

Ramke, Jacqueline et al. "Prevalence and Causes of Blindness and Low Vision among Adults in Fiji." Clinical \& Experimental Ophthalmology 40.5 (2012): 490-496. Wiley Online Library. Web. 5 May 2014.

Ramke, Jacqueline, Renee Du Toit, and Garry Brian. “An Assessment of Recycled Spectacles Donated to a Developing Country." Clinical \& Experimental 
Ophthalmology 34.7 (2006): 671-676. Wiley Online Library. Web. 12 Nov. 2013.

“Sustainable Projects | VOSH International.” Web. 19 May 2014.

"Use of Ready-Made Spectacles to Meet Visual Needs in a Low-Resource Adult Population." n. pag.

Vincent, Jerry E et al. "The Rationale for Shifting from a Voluntary Clinical Approach to a Public Health Approach in Addressing Refractive Errors." Clinical and Experimental Optometry 90.6 (2007): 429-433. Wiley Online Library. Web. 12 Nov. 2013.

Wilson, David A et al. "Real Cost of Recycled Spectacles." Optometry and vision science: official publication of the American Academy of Optometry 89.3 (2012): 304-309. NCBI PubMed. Web.

World Health Organization. "Global Data on Visual Impairments 2010." (2012): n. pag.

--.. "Sight Test and Glasses Could Dramatically Improve the Lives of 150 Million People with Poor Vision." (2006): n. pag.

Zheng, Yingfeng et al. "How Much Eye Care Services Do Asian Populations Need? Projection from the Singapore Epidemiology of Eye Disease (SEED) Study." Investigative Ophthalmology \& Visual Science 54.3 (2013): 2171-2177. www.iovs.org. Web. 12 Nov. 2013. 